\title{
How effective is ketamine in the management of chronic neuropathic pain?
}

\author{
Jack Williams Shteamer ${ }^{1}$, Mayson Augustus Callaway ${ }^{1}$, Parth Patel ${ }^{1}$ \& Vinita Singh *,1 (iD \\ ${ }^{1}$ Department of Anesthesiology, Emory University, Atlanta, GA 30322, USA \\ *Author for correspondence: Tel.: +1 404686 2410; Fax: +1 404686 4475; Vinita.Singh@emory.edu
}

\section{"Ketamine is a promising treatment for chronic neuropathic pain."}

First draft submitted: 5 August 2019; Accepted for publication: 12 August 2019; Published online: 15 October 2019

Keywords: analgesia $\bullet$ chronic pain $\bullet$ ketamine $\bullet$ neuropathic pain $\bullet$ pain $\bullet$ pain management

Neuropathic pain is a challenging pain disorder that physicians commonly encounter. Stemming from damage to nerves, cancerous invasion or dysregulatory patterns in the peripheral and central nervous system, the treatment of neuropathic pain is unique and difficult [1]. Procedures often fail to relieve the pain encountered in neuropathic conditions, and patients are frequently managed medically. Despite decades of research, the search continues for the ideal medication for the treatment of neuropathic pain.

The neurotransmitters and aberrant synapses involved in the pain pathways are diffuse. After peripheral nerve lesions, aberrant regenerative synapses may occur leading to spontaneously firing neurons producing allodynia and/or hyperalgesia. Peripheral nerve damage induces glial cells to release pro-inflammatory cytokines and glutamate, an NMDA receptor agonist [2]. With chronic nerve injury, redistribution of sodium and calcium channels can result in spontaneous firing of the neuron deemed peripheral sensitization [2]. Loss of afferent signals and peripheral sensitization can induce functional changes in the dorsal horn leading to central sensitization [3]. The activation and upregulation of dorsal horn excitatory NMDA receptors is believed to play a central role in neuropathic pain, allodynia and hyperalgesia. NMDA receptor antagonism results in analgesia by preventing central sensitization in dorsal horn neurons [4].

Ketamine is a potent NMDA antagonist which is frequently used in the treatment of acute and chronic pain, sedation, induction and maintenance of anesthesia, and ICU sedation [4]. It exerts its NMDA antagonism by binding to the phencyclidine receptor site when the channel is open [4]. With ketamine's ability to inhibit these receptors, it is postulated that ketamine can help treat chronic neuropathic pain [5]. Additionally, ketamine has been shown to be a rapid acting antidepressant, making it useful in the concomitant treatment of pain and depression [6]. While the elimination half-life of ketamine is $5.9 \mathrm{~h}$, after intravenous (iv.) bolus administration, its analgesic effects have been reported to last up to 12 weeks $[7,8]$. The drug is metabolized by hepatic CYP3A4 to mostly norketamine, which may contribute to its analgesic properties. It is commercially available as a racemic mixture in USA; however, the S-enantiomer (now available in USA in intranasal formulation for depression) [9] is four-times more potent than the R-enantiomer (and two-times more potent than the combination) [4]. Due to its lipid and water solubility, ketamine can be administered intravenously, by intramuscular and subcutaneous injection, transdermally, transmucosally and orally, although it has substantial first-pass metabolism and its oral bioavailability is $17-29 \%$ [10].

The administration of ketamine is not without side effects. The acute, dose-dependent, adverse effects of ketamine include psychotomimetic phenomena (e.g., hallucinations, nightmares), delirium, dizziness, visual changes, nystagmus, altered hearing, hypertension, tachycardia, hypersalivation, nausea and vomiting [4]. Its effect on intracranial pressure are debated, nonetheless, it should be used with caution in patients with concern for elevated intracranial pressure [11]. Its long-term frequent administration is associated with short- and long-term memory loss, urinary tract symptoms ('ketamine-induced vesicopathy'), transiently elevated liver enzymes and dependence [12].

The effectiveness of ketamine in treating chronic neuropathic pain, however, remains a debated issue. A recent meta-analysis of double blind randomized controlled trials (DB-RCT) utilizing ketamine for chronic neuropathic 
pain revealed mixed results. Six studies were included in their analysis, with total 99 subjects in the ketamine group and 96 in the placebo group. Intravenous (iv.) equivalent daily dosing ranged from 18 to $480 \mathrm{mg}$, and treatment length 1 to 90 days. 20 patients had spinal cord injuries, 18 had vascular ischemic pain, 39 had complex regional pain syndrome (CRPS), and 22 had neuropathic pain not defined. Five of the six trials administered ketamine for less than 11 days, while one trial administered ketamine over 90 days. The meta-analysis did not show a reduction in pain intensity at 4 weeks compared with placebo (mean difference [MD] -1.12, 95\%; confidence interval [CI] -2.33-0.09). Despite failing to reach their primary end point of pain reduction at 4 weeks, they did find significantly decreased pain intensity at 1, 2, 8 and 12 weeks. Of note, there was a statistically significant increase in psychedelic complications with ketamine use (relative risk $[R R]=5.35[2.64,10.81]$ ) $[8]$.

The treatment of CRPS with ketamine has been of particular interest to pain physicians. Sigtermans et al. (included in the aforementioned meta-analysis) studied 60 patients with CRPS-1 who were randomly allocated to receive $S(+)$-ketamine infusions or placebo. Patients were started on a rate of $1.2 \mu \mathrm{g} / \mathrm{kg} / \mathrm{min}$, which was titrated to a maximum of $7.2 \mu \mathrm{g} / \mathrm{kg} / \mathrm{min}$ for 5 days. Their primary outcome measured pain scores (NPRS) collected weekly, from baseline until week 12. Lowest pain scores occurred at week 1, with a greater reduction in patients treated with ketamine versus placebo (ketamine $2.68 \pm 0.51$ and placebo $5.45 \pm 0.48$ ). This effect lasted until week 11 . At week 12, there was no significant difference between the groups. There were significantly more side effects in the ketamine group, including nausea (63\%), vomiting (47\%), and psychomimetic effects (93\%). They did not find a significant improvement in functional status in ketamine group versus placebo [13].

Kiefer $e t$ al. looked at the ability of anesthetic dosages of iv. ketamine to treat CRPS. 20 patients with CPRS received an initial ketamine bolus of $1.5 \mathrm{mg} / \mathrm{kg}$, followed by intubation and mechanical ventilation. Patients remained intubated and ventilated for 5 days, while an iv. ketamine infusion was titrated from $3 \mathrm{mg} / \mathrm{kg} / \mathrm{h}$ up to a final dose of $7 \mathrm{mg} / \mathrm{kg} / \mathrm{h}$. At 1, 3, and 6 months mean pain were $93.5 \%, 89.4 \%$, and $79.3 \%$ of initial pain, respectively. Complete remission of CRPS occurred at 1 month in all patients, and by 6 months in 16 patients [14].

Eichenberger et al. examined the effects of ketamine, calcitonin, ketamine with calcitonin, or placebo on chronic phantom limb pain in a DB-RCT crossover study. During the study, 10 of the 20 patients received ketamine infusions $(0.4 \mathrm{mg} / \mathrm{kg}$ over $1 \mathrm{~h}$ once) alone. They found that both ketamine alone and ketamine with calcitonin reduced pain intensity by $50 \%$ or more in $60 \%$ of patients, versus $10 \%$ after calcitonin and placebo. This effect was no longer present by 48-h post infusion for ketamine or calcitonin [15].

In a study by Bosma et al., the effects of brain dynamics and temporal summation on response to ketamine infusion in chronic neuropathic pain patients were examined. 30 patients with neuropathic pain and 20 healthy controls underwent quantitative sensory testing and resting state fMRI at baseline. Intravenous ketamine (0.5$2 \mathrm{mg} / \mathrm{kg} / \mathrm{h}$; mean dose $1.1 \mathrm{mg} / \mathrm{kg} / \mathrm{h}$ ) was given for $6 \mathrm{~h} /$ day for 5 consecutive days. $50 \%$ of patients achieved pain relief at 1 month. Pretreatment temporal summation and dynamic connectivity was significantly higher in responders. The study suggests that brain dynamics and quantitative sensory testing can potentially help personalize ketamine therapies in chronic neuropathic pain patients [16].

In 2012, Huge et al. administered either 0.2 or $0.4 \mathrm{mg} / \mathrm{kg}$ intranasal S-ketamine to 16 patients with chronic neuropathic pain. Maximum pain reduction was noted at $60 \mathrm{~min}$ after administration, with $70 \pm 10 \%$ reduction in the $0.2 \mathrm{mg} / \mathrm{kg}$ group, and $61 \pm 13 \%$ reduction in the $0.4 \mathrm{mg} / \mathrm{kg}$ group. Patients underwent quantitative sensory testing before and after drug administration. However, there were no significant changes noted [17].

Ketamine has also been used topically. In a placebo-controlled DB-RCT by Lynch et al., topical $1 \%$ ketamine with $2 \%$ amitriptyline was used to treat patients with neuropathic pain. 92 patients were randomized to receive either placebo, $2 \%$ amitriptyline, $1 \%$ ketamine or a combination of $2 \%$ amitriptyline and $1 \%$ ketamine three-times a day for 3 weeks. $10 \%$ of the patients given ketamine exhibited a $50 \%$ or greater reduction in pain score after 3 weeks compared with $18 \%$ for placebo $\left(\chi^{2}[3]=1.1, p=0.76\right)$ [18]. Other studies, however, have shown different results. Rabi et al. performed an open label study on the usage of $10 \%$ topical ketamine for neuropathic pain in spinal cord injury patients. Five subjects at an outpatient rehabilitation hospital with spinal cord injuries resulting in neuropathic pain were given 10\% topical ketamine three-times a day for 2 weeks. After 2 weeks, all subjects had a decrease in their NPRS ranging from 14 to 63\% [19]. While sample sizes are small, the difference in the results of these two studies may be influenced by the strength of topical ketamine given.

Ketamine is a promising treatment for chronic neuropathic pain. The current understanding of neuropathic pain pathophysiology highlights ketamine's potential to treat this difficult illness. However, while clinical studies are generally positive, evidence is mostly limited to small RCTs with wide variability in patient population, dose, 
route of administration and length of treatment. Further high-quality clinical evidence is needed to definitively state if ketamine is beneficial in the treatment of chronic neuropathic pain.

Financial \& competing interests disclosure

Supported in part by the National Center for Advancing Translational Sciences of the National Institutes of Health under Award number UL1TR002378 and KL2TR002381. The content is solely the responsibility of the authors and does not necessarily represent the official views of the National Institutes of Health. The authors have no other relevant affiliations or financial involvement with any organization or entity with a financial interest in or financial conflict with the subject matter or materials discussed in the manuscript apart from those disclosed.

No writing assistance was utilized in the production of this manuscript.

\section{Open access}

This work is licensed under the Attribution-NonCommercial-NoDerivatives 4.0 Unported License. To view a copy of this license, visit http://creativecommons.org/licenses/by-nc-nd/4.0/

\section{References}

1. Colloca L, Ludman T, Bouhassira D et al. Neuropathic pain. Nat. Rev. Dis. Primers 3(1), 17002 (2017).

2. Wieseler-Frank J, Maier SF, Watkins LR. Central proinflammatory cytokines and pain enhancement. Neurosignals 14(4), 166-174 (2005).

3. Morgan CJA, Muetzelfeldt L, Curran HV. Consequences of chronic ketamine self-administration upon neurocognitive function and psychological wellbeing: a 1-year longitudinal study: the consequences of repeated ketamine use. Addiction 105(1), 121-133 (2010).

4. Quibell R, Prommer EE, Mihalyo M, Twycross R, Wilcock A. Ketamine*. J. Pain Symptom Manag. 41(3), 640-649 (2011).

5. O’Brien SL, Pangarkar S, Prager J. The use of ketamine in neuropathic pain. Curr. Phys. Med. Rehabil. Rep. 2(2), 128-145 (2014).

6. Zhang K, Hashimoto K. An update on ketamine and its two enantiomers as rapid-acting antidepressants. Exp. Rev. Neurother. 19(1), 83-92 (2019).

7. Peltoniemi MA, Saari TI, Hagelberg NM et al. Rifampicin has a profound effect on the pharmacokinetics of oral S-ketamine and less on intravenous S-ketamine. Basic Clin. Pharmacol. Toxicol. 111(5), 325-332 (2012).

8. Michelet D, Brasher C, Horlin A-L et al. Ketamine for chronic non-cancer pain: a meta-analysis and trial sequential analysis of randomized controlled trials. Eur. J. Pain 22(4), 632-646 (2018).

9. SPRAVATO ${ }^{\mathrm{TM}}$ (esketamine). Janssen Pharmaceutical (2018). www.spravato.com/

10. Aroni F, Iacovidou N, Dontas I, Pourzitaki C, Xanthos T. Pharmacological aspects and potential new clinical applications of ketamine: reevaluation of an old drug. J. Clin. Pharm. 49(8), 957-964 (2009).

11. Wang X, Ding X, Tong Y et al. Ketamine does not increase intracranial pressure compared with opioids: meta-analysis of randomized controlled trials. J. Anesth. 28(6), 821-827 (2014).

12. Middela S, Pearce I. Ketamine-induced vesicopathy: a literature review: ketamine and bladder. Int. J. Clin. Pract. 65(1), 27-30 (2011).

13. Sigtermans MJ, van Hilten JJ, Bauer MCR et al. Ketamine produces effective and long-term pain relief in patients with complex regional pain syndrome type 1. Pain 145(3), 304-311 (2009).

14. Kiefer R-T, Rohr P, Ploppa A et al. Efficacy of ketamine in anesthetic dosage for the treatment of refractory complex regional pain syndrome: an open-label Phase II study. Pain Med. 9(8), 1173-1201 (2008).

15. Eichenberger U, Neff F, Sveticic G et al. Chronic phantom limb pain: the effects of calcitonin, ketamine, and their combination on pain and sensory thresholds. Anesth. Analg. 106(4), 1265-1273 (2008).

16. Bosma RL, Cheng JC, Rogachov A et al. Brain dynamics and temporal summation of pain predicts neuropathic pain relief from ketamine infusion. Anesthesiology 129(5), 1015-1024 (2018).

17. Huge V, Lauchart M, Magerl W et al. Effects of low-dose intranasal (S)-ketamine in patients with neuropathic pain. Eur. J. Pain 14(4), 387-394 (2010).

18. Lynch ME, Clark AJ, Sawynok J, Sullivan MJL. Topical 2\% amitriptyline and 1\% ketamine in neuropathic pain syndromes: a randomized, double-blind, placebo-controlled trial. Anesthesiology 103(1), 140-146 (2005).

19. Rabi J, Minori J, Abad H, Lee R, Gittler M. Topical ketamine $10 \%$ for neuropathic pain in spinal cord injury patients: an open-label trial. Int. J. Pharm. Compd. 20(6), 517-520 (2016). 